\title{
Ectopic pituitary adenoma in the ethmoid sinus
}

\author{
Karuppiah Dharshini ${ }^{1}$, Noel Somasundaram ${ }^{2}$, Kamani Samarasinghe ${ }^{3}$, Chandra Jayasooriya ${ }^{4}$
}

Sri Lanka Journal of Diabetes Endocrinology and Metabolism 2011; 1: 34-36

\begin{abstract}
We describe an unusual case of ectopic pituitary adenoma in the nasal cavity. A 69-year-old man complaining of right side nasal bleeding had a polypoid tumor in the right nasal cavity. Findings of computed tomographic scanning and magnetic resonance imaging (MRI) showed that the tumor originated from the right ethmoidal sinus, occupied the nasal cavity, and extended to the floor of the right cranial fossa and a normal pituitary gland. He had normal hormonal assay. Histology suggested ectopic pituitary adenoma. Immuno histochemical assay was positive for pituitary factors and neuroendocrine markers.

Normal pituitary gland on MRI and the histology helped to establish the diagnosis of the ectopic pituitary adenoma. The patient underwent functional endoscopic sinus surgery (FESS) of the tumor followed by an uneventful recovery. The pathologic findings were comparable to those adenomas arising from the pituitary gland.
\end{abstract}

\section{Introduction}

Ectopic pituitary adenoma is a rare entity. By definition, it is a pituitary mass lesion outside the sella turcica ("ectopic") with a normal situated pituitary gland without any continuity with sella turcica.

Common age range is between $22-84$ years (mean, 52 years), and the usual presentations are airway obstruction, chronic sinusitis, epistaxis, visual field defects, headaches and some times with endocrinopathy: Cushing's syndrome, acromegaly, etc.

\section{Case report}

A sixty nine year old male with hypertension and mitral valve prolapse was admitted to ENT ward with a history of right sided nasal block and nasal discharge of two months duration and one episode of epistaxis.

Examination revealed a right side nasal growth.

\section{Investigations}

CT sinuses revealed an opacity of the ethmoidal sinus with associated bony destruction in the floor of the right cranial fossa and ethmoidal bone, suggesting a malignant neoplasm (Figure 1).

MRI brain showed features suggestive of malignant neoplasia in right ethmoid sinus with the rest of the brain including pituitary gland being normal (Figure 2).

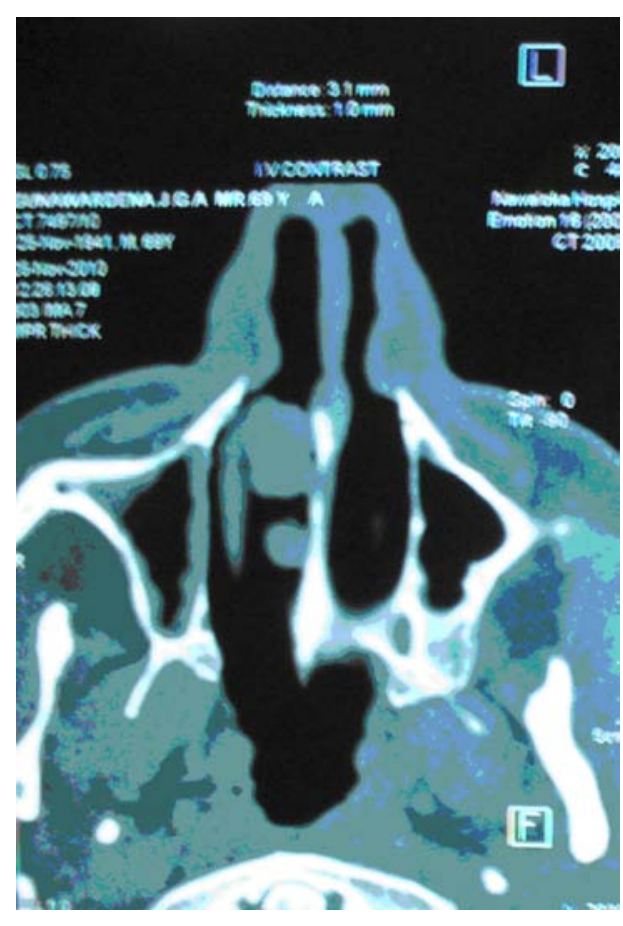

Figure 1.

Biopsy of the nasal growth revealed sheets and trabeculae of polygonal cells with regular nuclei and abundant granular cytoplasm compatible with a pituitary adenoma arising from an ectopic pituitary tissue in the nasopharynx.

${ }^{1}$ Senior Registrar in Endocrinology, ${ }^{2}$ Consultant Endocrinologist, ${ }^{4}$ Consultant ENT Surgeon, National Hospital of Sri Lanka, ${ }^{3} \mathrm{Head}$, Department of Pathology, Faculty of Medicine, Sri Jayawardenapura, Sri Lanka. 

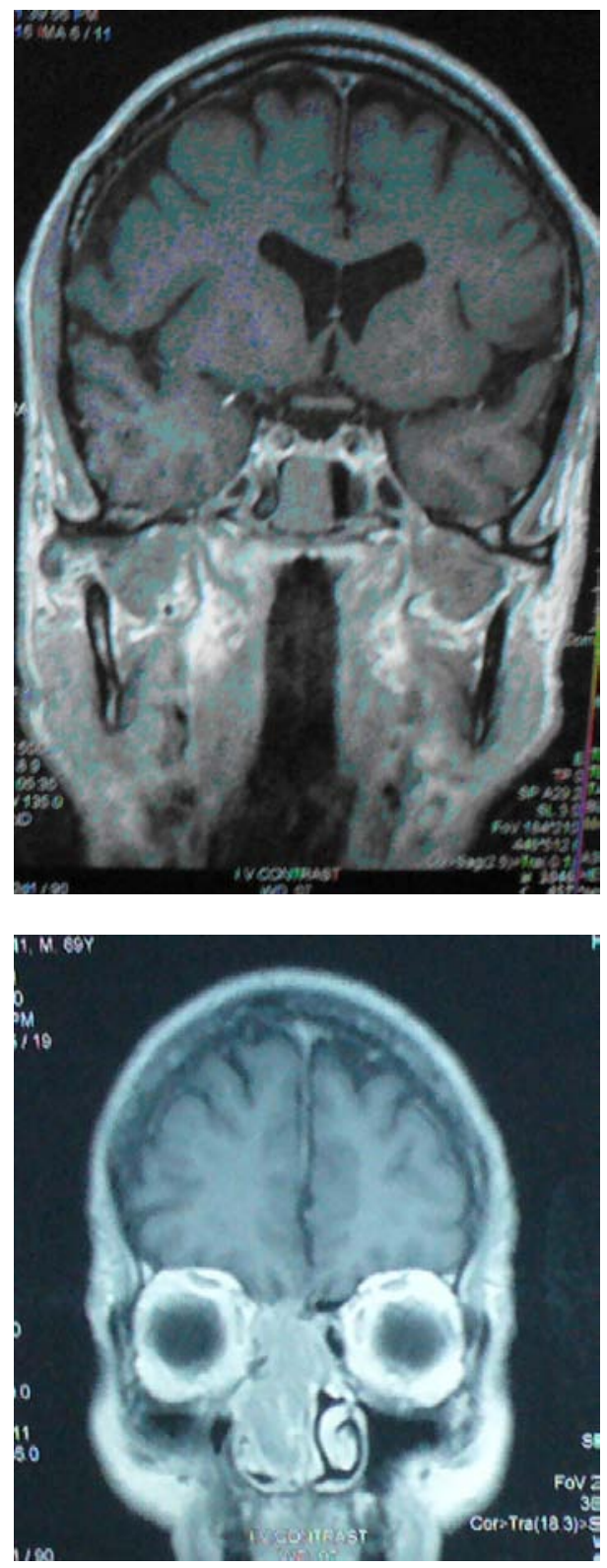

Figure 2.

He had normal hormonal assay including 9 AM serum cortisol $10.4 \mathrm{microgram} / \mathrm{dl}$, prolactin $6.15 \mathrm{ng} / \mathrm{ml}$, FSH 16.8 $\mathrm{miu} / \mathrm{ml}$ and LH $6.15 \mathrm{miu} / \mathrm{ml}$.

The diagnosis of ectopic pituitary adenoma of the nasal cavity was made.

\section{Management}

The patient underwent functional endoscopic sinus surgery (FESS) of the tumor under general anesthesia followed by an uneventful recovery.

Histology of excised growth suggested pituitary adenoma probably arising from ectopic pituitary tissue in nasopharynx. The tumor was not invading overlying nasal mucosa and immunohistochemical testing was positive for pituitary factors (Growth hormone and prolactin) and neuroendocrine markers (synaptophysin and chromogranin).

\section{Discussion}

The first case of ectopic pituitary adenoma was described in 1909 by Erdheim (1). The majority of these tumours are located at the level of the sphenoid sinus (approximately $40 \%$ ) or in the suprasellar region (approximately 33\%), other locations being sporadically found in the clivus, cavernous sinus, petrous bone, sphenoid bone, mid-nasal ductus, third ventricle, and left cerebral hemisphere (2-9).

Pituitary adenoma presenting as sinonasal tumor as in our patient is very rare and only three other such cases, involving the sinonasal tract are described (10). In none of the cases was the diagnosis of pituitary adenoma suspected clinically.

Ectopic pituitary adenoma has characteristic light microscopic and immune histochemical findings including neuroendocrine markers (chromogranin, synaptophysin, CD56) and Pituitary markers (Prolactin, ACTH, GH, FSH, LH, TSH).

Around 50\% are reactive for 2 or more hormones, $39 \%$ for single hormone and $11 \%$ are non-reactive (null cell).

Radiologically, ectopic pituitary adenomas may mimic other skull base lesions. Even histological diagnosis may be challenging; the differential diagnosis includes carcinoid, neuroendocrine carcinoma, paraganglioma, and carcinomas of the upper respiratory tract (6). Malignant transformation is exceptional (11). The majority of adenomas arising from ectopic hypophysial tissue are adrenocorticotrophin-secreting

Adenomas $(2,4,5,8)$. Surgical therapy is the mainstay of treatment and can be associated with postoperative radiotherapy whenever resection is incomplete.

\section{Conclusion}

This case illustrates a rare cause of sino nasal neoplasm. Pituitary adenomas may cause significant difficulties in histological diagnosis when presenting in unusual sites either as extension from an intrasellar lesion or as ectopic tumor. The clues to diagnosis are an endocrine growth pattern comprising tumor cells arranged in packets, ribbons, or rosettes, with prominent delicate vascularized stroma; a high index of suspicion; and immunohistochemical demonstration of neuroendocrine markers and pituitary hormones in tumor cells. A correct diagnosis is important because in contrast to neuroendocrine carcinoma as a whole or to poorly differentiated carcinoma, pituitary neoplasms have a much more favorable prognosis and a low metastatic potential. 


\section{References}

1. Pasquini E, Faustini M. Ectopic TSH-secreting pituitary adenoma of the vomerosphenoidal junction. European Journal of Endocrinology 2003; 148: 253-7.

2. Pernicone PJ, Scheithauer BW. Invasive pituitary adenoma and pituitary carcinoma. Diagnosis and Management of Pituitary Tumors 2001; 22: 369-85.

3. Anand VK, Osborne CM, Harkey HL. Infiltrative clival pituitary adenoma of ectopic origin. Otolaryngology Head and Neck Surgery 1993;108: 178-83.

4. Hou L, Harshbarger T, Herrick MK, Tse V. Suprasellar adrenocorticotropic hormone-secreting ectopic pituitary adenoma: case report and literature review. Neurosurgery 2002; 50: 618-25.

5. Lloyd RV, Chandler WF, Kovacs K, Ryan N. Ectopic pituitary adenomas with normal anterior pituitary glands. American Journal of Surgical Pathology 1986; 10: 546-52.

6. Luk IS, Chan JK, Chow SM, Leung S. Pituitary adenoma presenting as sinonasal tumor: pitfalls in diagnosis. Human Pathology 1996 ; 27 : 605-9.

7. Rasmussen P, Lindholm J. Ectopic pituitary adenomas. Clinical Endocrinology 1979; 11: 69-74.

8. Sanno N, Tahara S, Yoshida Y, Onose H, Wakabayashi I, Teramoto A. Ectopic corticotroph adenoma in the cavernous sinus: case report. Neurosurgery 1999; 45: 914-17.

9. Wong K, Raisanen J, Taylor SL, McDermott MW, Wilson $\mathrm{CB}$, Gutin PH. Pituitary adenoma as an unsuspected clival tumor. American Journal of Surgical Pathology 1995; 19: 900-903.

10. Van der Mey AG, van Seters AP, van Krieken JH, Vielvoye J, van Dulken $\mathrm{H}$, Hulshof JH. Large pituitary adenomas with extension into the nasopharynx. Report of three cases with a review of the literature. Annals of Otology, Rhinology and Laryngology 1989; 98: 618-24.

11. Hosaka N, Kitajiri S-I, Hiraumi H, Nogaki H, Toki J, Yang $\mathrm{G}$, et al. Ectopic pituitary adenoma with malignant transformation. American Journal of Surgical Pathology 2002; 26: 1078-82. 